\title{
Desenvolvimento do conceito intuitivo de limites por meio da
}

\section{Assimilação Solidária}

Development of the intuitive concept of limits through Solidary Assimilation

\author{
Eduardo Rafael Zimdars ${ }^{1}$ \\ Regina Helena Munhoz ${ }^{2}$
}

\section{Resumo}

Este artigo tem como objetivo analisar as possíveis influências da Assimilação Solidária (AS) no processo de ensino e aprendizagem do conceito intuitivo de limites. A AS é uma proposta que visa romper com o ensino tradicional de matemática, modificando as relações estabelecidas em sala de aula. Por isso, é alicerçada em um contrato de trabalho que apresenta todas as regras e formas de promoção do estudante por meio do seu trabalho colaborativo em sala. Assim, os conteúdos são estudados em grupos que devem resolver os problemas que constam nas fichas de trabalho. Especificamente, neste artigo, analisamos uma aula em AS sobre o conceito intuitivo de limites, na turma de Cálculo Diferencial e Integral I, do curso de Licenciatura em Matemática da UDESC do segundo semestre de 2017, composta por 37 alunos. Os resultados permitiram inferir que a AS possibilita aos estudantes a aprendizagem intuitiva de limites de modo mais autônomo, tornando-os corresponsáveis, em conjunto com o professor, de todo o processo.

Palavras-chave: Assimilação Solidária. Limites. Conceito Intuitivo.

\section{Introdução}

Atualmente, o ensino do Cálculo Diferencial e Integral (CDI) tem se tornado tema de diversas pesquisas, dissertações, teses e ensaios acadêmicos. Essa incidência é justificada pela importância que o CDI assume nas mais variadas áreas de conhecimento, como, por exemplo, aplicações em modelagem de fenômenos, estimativas, na física, economia, biologia, dentre outras.

Em vista disso, quando se fala em ensino de CDI, tem-se constatado um alto índice de não aproveitamento - reprovação - por parte dos alunos ingressantes no

\footnotetext{
${ }^{1}$ Mestre em Ensino de Ciências, Matemática e Tecnologias pela Universidade do Estado de Santa Catarina. Professor da Rede Pública Estadual de SC; erzimdars@gmail.com.

${ }^{2}$ Doutora em Educação para a Ciência e Matemática pela Universidade Estadual Paulista Júlio de Mesquita Filho. Professora da Universidade do Estado de Santa Catarina; regina.munhoz@udesc.br.
} 
Ensino Superior, como mostram as pesquisas de Barufi (1999), Lopes (1999), Rezende (2003) e Henning, Moro e Pacheco (2013) que apresentam estes dados de diversas Universidades. Segundo Pagani e Allevato (2014), esse fato - índices altos de reprovação em CDI - constitui a principal motivação para a maioria das pesquisas na área. Algumas dessas pesquisas, conjuntamente com a motivação nos índices de reprovação, almejam mudar a posição passiva dos estudantes durante as aulas para uma participação mais ativa, na qual eles sejam corresponsáveis pelo processo de aprendizagem.

Um desses pesquisadores é Roberto Ribeiro Baldino que tem proposto, desde a década de 1980, que as relações da sala de aula sejam readaptadas. Para isso, diz (BALDINO, 1994) que é necessário romper com o Ensino Tradicional Vigente (ETV), sendo uma das formas de se fazer isso, por meio da Pedagogia da Assimilação Solidária (AS), desenvolvida por ele.

Com base nisso, a pergunta norteadora dessa pesquisa é "como ocorre 0 processo de ensino e aprendizagem do conceito intuitivo de limites, por meio da AS, em uma turma de CDI I?". Tendo como objetivo de pesquisa analisar quais as possíveis influências da AS no processo de ensino e aprendizagem do conceito intuitivo de limites. Para tanto, apresentaremos a AS, seus objetivos e princípios; a proposta desenvolvida para a turma de CDI I da Licenciatura em Matemática da UDESC, a metodologia adotada no artigo e para a análise dos dados; a discussão dos resultados, com base na literatura sobre o tema; finalizando com considerações sobre o estudo feito.

\section{Pedagogia da Assimilação Solidária}

Baldino (1994) defende que no ETV o processo de ensino e aprendizagem é centrado no professor e no conteúdo, a memorização é a medida da aprendizagem, além de existir um contrato didático implícito, que mantém professor e alunos atuando conforme o sistema vigente. Nesse contrato, o professor mostra domínio do conteúdo ministrado, espera que o aluno participe com perguntas, frequente o mínimo de aulas exigido para aprovação e, principalmente, saiba 
resolver as questões da prova escrita. Em contrapartida, o aluno espera que 0 professor não registre suas ausências, o que muitas vezes ocorre; não exija que faça outras atividades senão a prova e; no máximo, participe da aula com perguntas. Por isso, por meio desse contrato, é aprovado, muitas vezes, o aluno que sabe adequar-se as regras, sem que necessariamente tenha construído conhecimento matemático (BALDINO, 1994, 1995; SILVA, 1997).

Por conta desses fatores, Baldino $(1994,1998,2001)$ desenvolveu ao longo de seus estudos a AS que tem como objetivo romper com o ETV, democratizando a sala de aula. Assim, propõem que todos os critérios de avaliação estejam em um contrato de trabalho aprovado pelos alunos, de forma conjunta. E que a avaliação deixe de ser do produto final - prova escrita, passando a considerar todo o percurso da aprendizagem para analisar o desenvolvimento do estudante (BALDINO, 2001).

Consequentemente, a AS é uma forma de considerar como critério de avaliação, além do conteúdo matemático, o trabalho coletivo produzido em sala de aula. Na AS "o foco da aprendizagem está no aluno, contrapondo o ETV, cujo o principal foco é no conteúdo e no professor” (SILVA, 1997, p. 14).

Essa proposta torna a sala de aula um ambiente democratizado, por dois motivos principais. O primeiro é que a AS é proposta, não imposta, como Baldino (2001) destaca. Nesse sentido, o aluno que quiser, poderá permanecer no ETV, sem danos em relação a nota obtida. $O$ segundo motivo é que os alunos, enquanto grupo, tem autonomia para aceitar, recusar e sugerir mudanças no contrato de trabalho, que é discutido e votado por todos. Considerando esses aspectos, a aprendizagem de conteúdos matemáticos não é mais isolada, mas atrelada a uma aprendizagem pautada na democracia, criticidade, atuação social dos estudantes - conforme a Educação Matemática Crítica - e no trabalho coletivo dos grupos conforme a aprendizagem colaborativa (SKOVSMOSE, 2000; BALDINO, 2001; TORRES, 2004).

Desse modo, a sala de aula está em AS se houver: "[...] a medida da duração e a avaliação da qualidade do trabalho de aprendizagem como critério subsidiário de aprovação explícito, independente dos critérios de avaliação de conteúdo" 
(BALDINO, 2001, p. 2). O trabalho de aprendizagem é o percurso que se faz para alcançá-la, mesmo que não se chegue ao nível que se esperava. Assim, a avaliação não é a medida do resultado, mas da quantidade de tempo despendida para estudar, em coletividade, um conteúdo, discuti-lo e, em partes ou totalmente, entendê-lo. Logo, ela - a avalição - retrata como o aluno trabalhou e como foi a postura do grupo perante a aprendizagem solidária: "Trata-se, pois, de um projeto político que se realiza a partir da sala de aula" (lbid., p. 3).

Para que seja implementada a AS são necessários alguns princípios básicos que não podem ser eliminados ou modificados: o trabalho em grupo com aprendizagem solidária; a avaliação com base na qualidade do trabalho, não no resultado; supremacia do grupo de todos os alunos (grupão) em relação aos indivíduos (BALDINO, 2001; SILVA, 1997). A modificação destes princípios, segundo Baldino (1998), cujo pensamento corroboramos, descaracterizaria a AS e retornaria ao ETV. Com base nesses princípios - da AS, propomos uma intervenção em uma turma de Licenciatura de Matemática da UDESC, que será apresentada na próxima seção deste artigo.

\section{Proposta desenvolvida e metodologia adotada}

Como mencionado, a turma de CDI I do curso de Licenciatura em Matemática da UDESC foi o cenário de investigação para uma dissertação de mestrado (ZIMDARS, 2018), na qual foi proposta uma intervenção para o estudo de limites por meio da AS, com os princípios mostrados nas seções anteriores. Conforme a AS, cada aula é composta de uma ficha de trabalho com problemas sobre limites, uma ficha de sugestões, feitas pelo professor, indicando caminhos e referências para auxiliar os grupos de trabalho nas resoluções e uma ficha de respostas.

Desse modo, ao todo, foram trabalhadas oito aulas, de duas horas/aula cada, para o estudo de limites, das quais analisaremos, especificamente, neste artigo, duas aulas, sobre o conceito intuitivo de limites. As atividades utilizadas estão presentes na ficha de trabalho 1 - FT1. O objetivo da FT1 era elucidar de 
forma intuitiva o conceito de limite. Para isso foram escolhidos dois problemas: a área do fractal Tapete de Sierpinski e o outro sobre a capitalização contínua: Agiota de Roma. O primeiro problema pedia que os grupos determinassem a área do tapete a cada iteração, encontrando uma forma genérica ao final. O segundo problema tinha como objetivo que os grupos analisassem o que ocorria com 0 montante quando o período de capitalização diminuía.

A turma composta por 37 alunos ${ }^{3}$, para a intervenção, foi dividida em equipes - de 2 a 4 integrantes - formando no total 9 grupos, escolhidos pelo pesquisador com base na nota da primeira avaliação da disciplina, conforme previa o contrato de trabalho vigente. Estes grupos foram nomeados por letras maiúsculas $(A, B, \ldots$, I) e cada integrante pela letra e um número, por exemplo, A1, J3, etc.

A metodologia adotada durante o processo, que tem como objetivo analisar quais as possíveis influências da AS na aprendizagem do conceito intuitivo de limites, é qualitativa (BOGDAN; BIKLEN, 1994). Em relação aos procedimentos, é uma pesquisa participante (GIL, 2008), na qual o pesquisador e os investigados atuam de forma conjunta, contribuindo no processo como um todo.

Os dados analisados são as atividades desenvolvidas na FT1 e a postura dos grupos e dos estudantes no que tange os objetivos da AS, como vemos no quadro 1. Todos esses critérios de análise, no início da intervenção, foram apresentados aos alunos, estando presentes no cabeçalho das fichas de trabalho. Além disso, os estudantes responderam um questionário com perguntas abertas e fechadas, avaliando a intervenção realizada.

Para analisarmos estes dados utilizamos a análise de conteúdo, proposta de Bardin (1977). Segundo, Santos e Dalto (2012), diversos professores e pesquisadores têm desenvolvido seus trabalhos com base na exploração da produção escrita dos alunos. O objetivo dessa metodologia é "a construção de inferências sobre seus conhecimentos, em processos recursivos de construção de unidades de análises e categorizações" (SANTOS; DALTO, 2012, p. 2). Assim, divididos em duas categorias: a primeira sobre os itens do quadro 1 e a segunda

\footnotetext{
${ }^{3} \mathrm{Na}$ presente aula compareceram 31 alunos.
} 
sobre as resoluções propostas pelos grupos para os problemas das FT1. As categorias e subcategorias são apresentadas no quadro 2 e serão investigadas para cada grupo formado na aula de CDI1.

- Itens individuais (X para sim): ( ) Faltou; ( ) Chegou atrasado; ( ) Saiu mais cedo; ( ) Não trouxe o material de consulta; ( ) Chamou o professor sem consentimento do grupo;

( ) Atrapalhou o rendimento do grupo; ( ) Não conhecia ou desrespeitou o contrato de trabalho; ( ) Falta de comprometimento com a aprendizagem.

- Itens do grupo: (marcar a quantidade de ocorrências ou X para sim): ( ) Nem todos os membros sabiam perguntar ou explicar o que já haviam feito; ( ) Não aguardaram a sua vez de atendimento; ( ) Trabalho feito de forma individual; ( ) Algum componente está atrasado ou adiantado em relação ao grupo; ( ) Consultaram a ficha resposta antes de finalizar a atividade;

( ) Tempo de efetivo trabalho (medido em horas).

Quadro 1: Itens da FT sobre a postura do grupo e do estudante

Fonte: dos autores, 2018.

\begin{tabular}{|c|c|}
\hline Categorias & Subcategorias \\
\hline \multirow{2}{*}{$\begin{array}{l}\lambda \text { - Perfil dos grupos, em } \\
\text { relação a metodologia da AS }\end{array}$} & $\begin{array}{c}\lambda 1 \text { trabalho realizado de forma } \\
\text { colaborativa }\end{array}$ \\
\hline & $\begin{array}{l}\lambda 2 \text { cumprimento das (outras) regras } \\
\text { do contrato }\end{array}$ \\
\hline \multirow{5}{*}{$\begin{array}{l}\varphi \text { - Desenvolvimento do } \\
\text { grupo em relação ao } \\
\text { conteúdo das FT }\end{array}$} & $\begin{array}{l}\varphi 1 \text { ficha totalmente resolvida } \\
\text { corretamente }\end{array}$ \\
\hline & $\begin{array}{l}\text { Q2 ficha com metade ou mais dos } \\
\text { problemas resolvidos corretamente }\end{array}$ \\
\hline & $\varphi 3$ ficha parcialmente resolvida \\
\hline & $\varphi 4$ ficha totalmente errada \\
\hline & $\varphi 5$ ficha em branco \\
\hline
\end{tabular}

Quadro 2: Categorias e Subcategorias de Análise

Fonte: dos autores, 2018.

\section{Discussão dos resultados}

Nesta seção apresentaremos os dados e suas respectivas análises. Para isso, conforme a descrição da metodologia de análise dos dados, tivemos duas categorias, $\lambda$ e $\varphi$, que serão analisadas nos itens 4.1 e 4.2 , respectivamente. 


\subsection{Desenvolvimento dos grupos em relação aos termos da AS - categoria $\boldsymbol{\lambda}$}

Conforme mencionado, essa categoria corresponde ao desenvolvimento dos grupos em relação as regras do contrato de trabalho, avaliando os itens do quadro 1, presentes no início de cada FT. Dessa forma, tivemos a subcategoria $\lambda 1$ trabalho realizado de forma colaborativa, na qual analisamos três itens: tempo de efetivo trabalho, trabalho realizado de forma individual e integrantes adiantados/atrasados em relação ao grupo.

Todos os grupos (9), tiveram o mesmo tempo efetivo de trabalho, visto que nenhum integrante chegou atrasado, saiu adiantado ou interrompeu o trabalho durante a aula. Já em relação ao trabalho individual, pelo desenvolvimento da ficha individual de cada integrante, notamos que os grupos $E$, F e I responderam alguns itens sem colaboração entre os integrantes. O grupo $E$ era a única dupla da sala, o que pode ter influenciado nesse resultado, visto que Baldino (1998) sugere que na AS não se tenha a formação de duplas, justamente por esse fato. Em relação ao grupo $F$, os integrantes não tiveram entrosamento algum, até mesmo cogitaram a possibilidade de formarem outro grupo de trabalho, o que foi considerado nas aulas seguintes. Por fim, o grupo E, mesmo mantendo diálogo entre os integrantes e até com o pesquisador, desenvolveu trabalho individual em alguns itens, com a preocupação de finalizar todos os problemas.

Os grupos que tiveram integrantes adiantados/atrasados foram os grupos $D$, $\mathrm{E}, \mathrm{F}$ e I. Percebemos que, dado o trabalho individual do $\mathrm{E}, \mathrm{F}$ e I, provavelmente seus integrantes não desenvolvam de forma igual a ficha. Já em relação ao $D$, isso aconteceu porque poucos minutos antes da plenária os alunos desta equipe, com mediação do pesquisador, perceberam que estavam resolvendo a questão do Tapete de Sierpinski de forma equivocada, por isso, alguns mantiveram a forma que resolveram e os demais apagaram e refizeram, não tendo tempo para finalizar. Os demais grupos mantiveram o trabalho colaborativo da forma como se esperava, mesmo não terminando todas as questões ou cometendo erros na resolução. $A$ 
importância dessas análises é que para a AS, o trabalho é do grupo, ou seja, por meio da colaboração e diálogo os problemas devem ser resolvidos.

\subsection{Desenvolvimento do conceito intuitivo de limite -}

\section{categoria $\varphi$}

Além da metodologia da AS, verificada anteriormente, temos a categoria $\varphi$ que classifica os grupos de acordo com os problemas resolvidos. Tivemos a divisão conforme o quadro 3.

\begin{tabular}{|c|c|}
\hline Subcategoria & Grupos \\
\hline$\varphi 1$ ficha totalmente resolvida corretamente & nenhum grupo \\
\hline $\begin{array}{c}\varphi 2 \text { ficha com metade ou mais dos problemas } \\
\text { resolvidos corretamente }\end{array}$ & $\mathrm{A}, \mathrm{C}, \mathrm{H}$ \\
\hline$\varphi 3$ ficha parcialmente resolvida & $\mathrm{B}, \mathrm{D}, \mathrm{E}, \mathrm{G}$ \\
\hline$\varphi 4$ ficha totalmente errada & $\mathrm{F}, \mathrm{I}$ \\
\hline$\varphi 5$ ficha em branco & nenhum grupo \\
\hline
\end{tabular}

Quadro 3: Classificação dos Grupos nas Subcategorias de $\varphi$ - FT1

Fonte: dos autores, 2018.

Sobre nenhum grupo ter resolvido completamente a FT1, percebemos que o tempo de aula despendido para organização dos grupos foi considerável, fazendo com que não fosse possível resolver os dois problemas. Algumas equipes começaram o segundo problema, mas nenhuma finalizou nem o primeiro item construção do quadro. Porém, todas as equipes do $\varphi 2$ - A, C, H - resolveram corretamente o problema do Tapete de Sierpinski, concluindo de forma similar com generalizações equivalentes, como mostra a figura 1 .

Além disso, todas essas equipes deduziram que na questão 7 - calcular a área em cada iteração ${ }^{4}$ considerando o lado do quadrado inicial igual a 1u.c. bastava substituir o valor de I por 1 na forma generalizada encontrada. Bem como, tiveram respostas similares para questão 8 - justificar o que acontece com a área depois de inúmeras iterações, que são apresentadas no quadro 4, mais adiante.

$\mathrm{Na}$ terceira categoria - ficha parcialmente resolvida, composta pelos grupos $B, D, E$ e $G$, as equipes $B, E$ e $G$ resolveram até a questão 7 de forma correta,

\footnotetext{
${ }^{4}$ Iteração: repetição, ato de repetir um mesmo processo.
} 
similarmente ao mostrado na figura 1, porém erraram (grupo B) ou deixaram em branco (grupos E, G) a questão 8. Já a equipe D errou antes da generalização da área do tapete, na segunda iteração, chegando a uma área que não correspondia a área do Tapete, porém respondeu corretamente a questão 8.

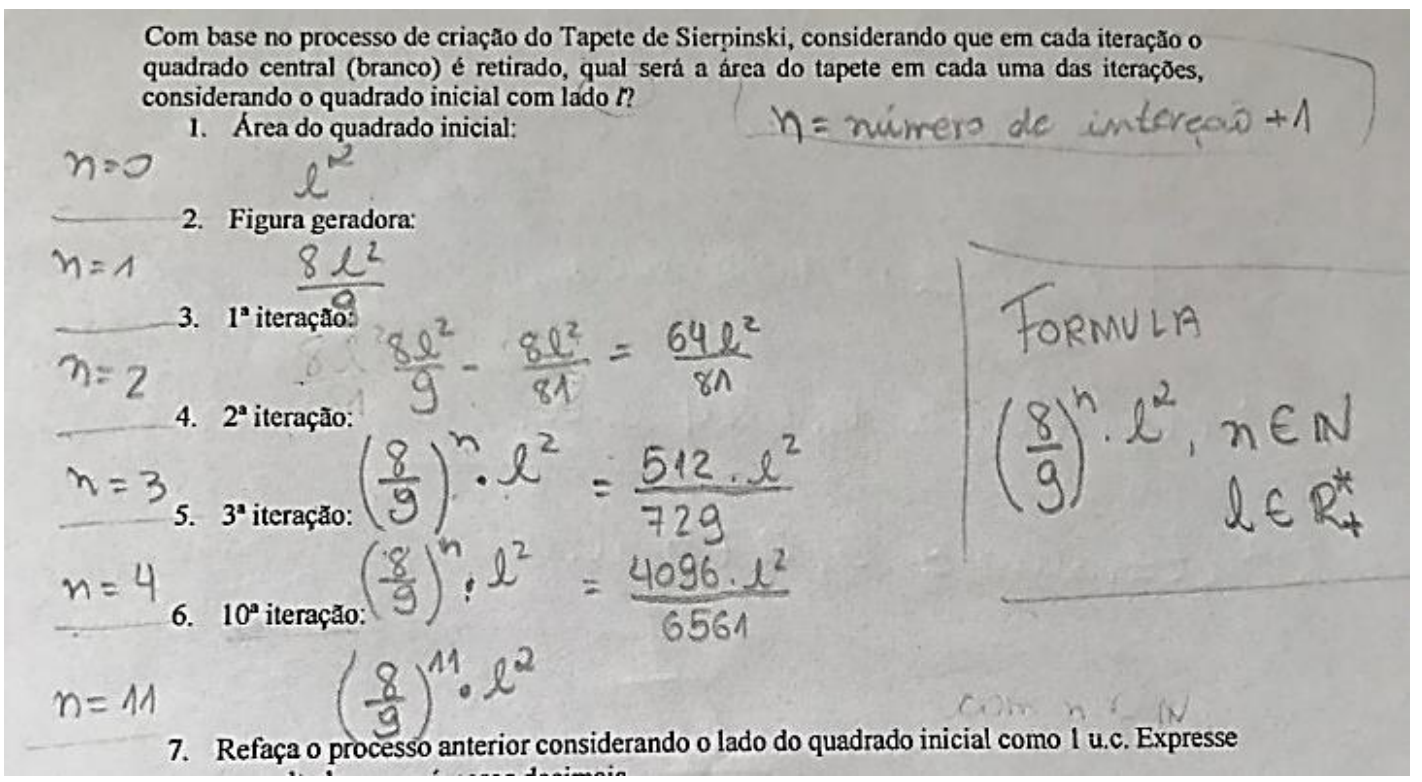

Figura 1: Desenvolvimento da questão A da FT1, Participante C4 Fonte: dos autores, 2018.

As últimas duas equipes, $\mathrm{F}$ e I, presentes na categoria ficha totalmente errada, acabaram não conseguindo desenvolver a questão. Os erros foram de interpretação e de simplificação das frações, como vemos na figura 2, da resolução do integrante 12, como exemplo.

Além da categorização apresentada, o quadro 4 mostra as repostas de cada grupo para a questão 8 , que pedia sobre o que aconteceria com a área do Tapete após um número muito grande de iterações, ou seja, a questão "chave" do problema. As repostas foram escolhidas aleatoriamente dos integrantes de cada equipe.

Muito embora algumas equipes não tenham conseguido resolver toda a FT1 de forma correta, os problemas se mostraram pertinentes ao estudo de limites, uma vez que ideias intuitivas puderam ser discutidas nos grupos. Sobre isso, Baldino (2001) explica que os problemas das fichas de trabalho têm como propósito o 
desenvolvimento dos estudantes em um determinado tema. Assim, diferente dos exercícios utilizados na perspectiva do ETV que são inúmeros e medidos de forma quantitativa, as fichas de trabalho propõem que aos estudantes sejam dados problemas que envolvam o conceito estudado, sem necessariamente resolver um número excessivo de questões.

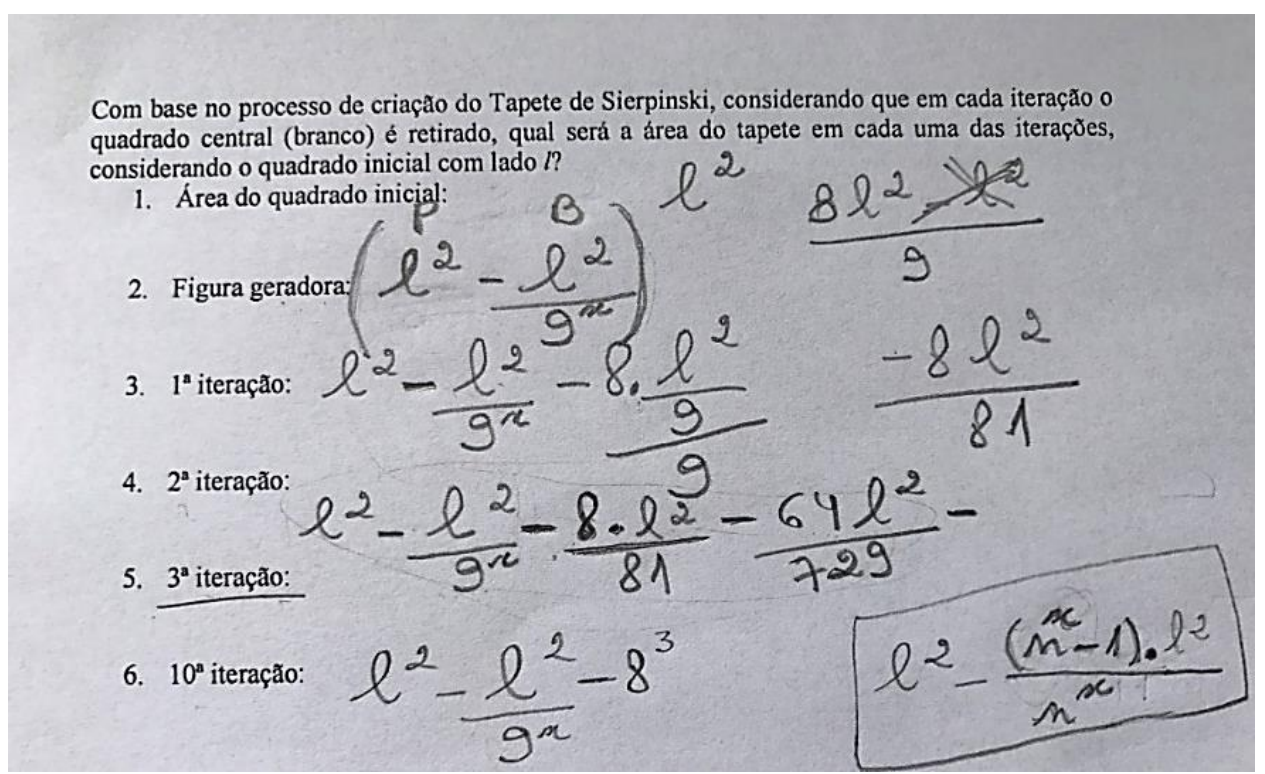

Figura 2: Desenvolvimento da questão A da FT1, Participante I2 Fonte: dos autores, 2018.

\begin{tabular}{|c|l|}
\hline Grupo & \multicolumn{1}{c|}{ Resposta questão 8 } \\
\hline A & $\begin{array}{l}\text { Após um número grande de iterações, a área ficaria cada vez } \\
\text { menor. Após infinitas interações (sic) a área ficaria próxima de } \\
\text { zero, mas nunca nula, pois a área inicial sempre será maior que } \\
\text { a área retirada. (A4, sujeito de pesquisa, 2017). }\end{array}$ \\
\hline \multirow{3}{*}{ B } & $\begin{array}{l}\text { Com o aumento do número de iterações a área do tapete diminui } \\
\text { de forma exponencial. Com infinitas iterações a área se aproxima } \\
\text { de um numero infinitamente próximo de 0,5 u.a. sem nunca } \\
\text { alcançar esse número. Pois a cada iteração você vai retirando } \\
\text { menos área, de forma com que a área do tapete nunca será nula. } \\
\text { (B1, sujeito de pesquisa, 2017). }\end{array}$ \\
\hline C & $\begin{array}{l}\text { A área se aproxima cada vez mais de zero. Desta forma, a área } \\
\text { após iterações infinitas é zero. Todavia, como infinito é apenas } \\
\text { uma noção e não um número, a área nunca será nula. (C4, } \\
\text { sujeito de pesquisa, 2017). }\end{array}$ \\
\hline
\end{tabular}




\begin{tabular}{|l|l|}
\hline $\mathrm{D}$ & $\begin{array}{l}\text { Sempre tenderá a 0, mas nunca será (D3, sujeito de pesquisa, } \\
\text { 2017). }\end{array}$ \\
\hline $\mathrm{E}$ & Em branco \\
\hline $\mathrm{F}$ & Em branco \\
\hline $\mathrm{G}$ & Em branco \\
\hline $\mathrm{H}$ & $\begin{array}{l}\text { Após um grande número de iterações a área seria bem menor. } \\
\text { Para infinitas iterações teríamos que a área seria } l^{2}\left(\frac{8}{9}\right)^{\infty+1} . \text { Nunca } \\
\text { será nula, pois não existe } \mathrm{n} \text { tal que } l^{2}\left(\frac{8}{9}\right)^{n+1}=0, \text { já que uma } \\
\text { função exponencial tem assíntota horizontal em } \mathrm{y}=0 . \text { (H3, sujeito } \\
\text { de pesquisa, 2017). }\end{array}$ \\
\hline $\mathrm{I}$ & Em branco \\
\hline
\end{tabular}

Quadro 4: Respostas dos grupos para a questão sobre o comportamento da área após inúmeras iterações

Fonte: dos autores, 2018.

À vista disso, o Tapete de Sierpinski ${ }^{5}$ foi útil para entender o conceito intuitivo de limites, visto que a sua área não poderia ser zero, tendo limite nesse valor. Sobre as repostas incoerentes, as fichas de trabalho subsequentes, segundo Baldino (1998), devem abarcar problemas/situações que permitam aos grupos voltarem a estudar esses conceitos, bem como, nesse momento, o professor pode intervir auxiliando o grupo. Nesse sentido, além da devolutiva das fichas de trabalho com indicações aos grupos, durante a plenária o professor-pesquisador discutiu a resolução da ficha.

\section{Considerações finais}

Conforme o objetivo deste artigo - análise das influências da AS no ensino e aprendizagem de limites, percebemos, a partir dos dados, percepções dos estudantes - por meio de questionário - e do pesquisador durante a intervenção, alguns aspectos importantes. De modo geral, todos os estudantes aceitaram 0 contrato de trabalho, mas, presumidamente, podemos perceber a formação de dois

\footnotetext{
${ }^{5}$ Focamos a análise nas respostas desse problema, visto que o problema $B$ não pode ser avaliado, já que os grupos não tiveram tempo de fazê-lo.
} 
grupos distintos: aqueles que foram favoráveis a AS e aqueles que foram contrários.

Em relação ao primeiro grupo, com as opiniões tecidas nos questionários e de modo oral durante a plenária, verificamos que foi ao encontro do que se espera que a AS, entre outros aspectos, fomente em sala de aula. Um dos participantes, questionado sobre a intervenção realizada, disse que: "Você se torna mais autônomo em relação a aprendizagem" (H1, sujeito de pesquisa, 2017). Entendemos que a autonomia, nesse contexto da AS, está relacionada em se tornar capaz de pesquisar em livros e apostilas a fim de resolver os problemas das fichas, mas ainda em saber que o processo de aprendizagem é de responsabilidade de cada integrante do grupo, assim como as decisões da sala de aula, democraticamente aceitas ou recusadas.

Ainda no primeiro grupo, participantes destacaram a importância do trabalho em grupo, conforme vemos: "Trocando ideias com os colegas e resolvendo exercícios se tem uma melhor ideia do que aprendeu e onde tem dúvida" (C1, sujeito de pesquisa, 2017). Ao encontro disso, o pesquisador percebeu, enquanto mediador, que as relações estabelecidas nos grupos contribuíram para a construção do conceito intuitivo de limite pelos próprios estudantes. Uma vez que utilizaram a aula para estudar e compreender conceitos, muitas vezes básicos, mas importantes para o estudo de limites.

Por sua vez, os participantes elencados ao segundo grupo são aqueles que não foram favoráveis a AS. Esses estudantes, em sua maioria, entenderam que a AS não contribuiu de forma positiva com a aprendizagem. Conforme vemos na opinião de um dos participantes, pois justificou que na AS se perde tempo discutindo os problemas com o grupo e durante a plenária, dizendo que: "Com o tempo gasto aprendendo por conta própria poderíamos ter avançado muito mais (e sem tanta confusão) com aulas normais" (D3, sujeito de pesquisa, 2017).

Percebemos que os argumentos deste segundo grupo - contrários a AS tiveram influência do ETV, pois os estudantes consideram mais proveitoso para sua aprendizagem que o professor faça a explanação do conteúdo, direcione o trabalho 
dizendo onde devem pesquisar e como devem resolver os problemas. Esse fato também foi percebido por Silva (1998), que realizou uma pesquisa com objetivos similares aos nossos. A autora relata que os estudantes requeriam a explanação do conteúdo no início da aula, enquanto que na AS o objeto da explanação, ao final da aula, é formalizar algumas questões e permitir que os grupos sanem suas dúvidas.

Assim, mesmo aceitando o contrato de trabalho, entendemos que esses estudantes gostariam que a aula ocorresse conforme o ETV, ou ainda não perceberam os objetivos da AS. Além disso, com a mediação durante as aulas e análise das fichas de trabalho, o pesquisador pode perceber que a maioria dos participantes contrários a AS, esteve nos grupos com certa dificuldade de relacionamento. Caso a disciplina toda fosse trabalhada em AS, para contornar essa situação, seria necessário readequar os grupos, respeitando o critério da nota.

Por fim, aos professores que queiram implementar a AS em suas aulas e utilizar este artigo com base, é importante destacarmos alguns outros aspectos. Desse modo, o objetivo principal da AS é romper com o ETV, modificando a dinâmica da sala de aula. Logo, não se pode ter como objetivo central minimizar os índices de reprovação, tema amplamente tratado em pesquisas sobre o ensino de Cálculo. Também, é importante entender que o trabalho dos grupos, o tempo da plenária e, principalmente, a participação democrática dos estudantes no grupão são intrínsecos e indissociáveis da AS.

\section{Referências}

BALDINO, Roberto Ribeiro. Assimilação solidária onze anos depois. Grupo de Pesquisa-Ação em Educação Matemática. Unesp: Rio Claro, 1994.

BALDINO, Roberto Ribeiro. Assimilação Solidária: escola, mais-valia e consciência cínica Educação em Foco, Juiz de Fora, Editora da UFJF, v.3, n. 1, p. 39-65, mar. /ago. 1998.

BALDINO, Roberto Ribeiro. Assimilação Solidária. Grupo de Pesquisa-Ação em Educação Matemática. Unesp: Rio Claro, 2001.

BARDIN, Laurence. Análise de conteúdo. Tradução: Luís Antero Reto, Augusto Pinheiro. São Paulo: Edições 70, 1977. 
BOGDAN, Robert C; BIKLEN, Sari K. Investigação Qualitativa em Educação: uma introdução a teoria e aos métodos. Portugal: Porto Editora, 1994.

GIL, Antônio, C. Métodos e técnicas de pesquisa social. 6 ed. São Paulo: Atlas, 2008.

PAGANI, Érica M. L.; ALLEVATO, Norma S. G.. Ensino e aprendizagem de Cálculo Diferencial e Integral: um mapeamento de algumas teses e dissertações produzidas no Brasil. VIDYA, 34(2), jul./dez., 2014 - Santa Maria.

SANTOS, João R.V dos; DALTO, Jader O. Sobre a análise de conteúdo, análise textual discursiva e análise narrativa: investigando produções escritas em matemática. Anais do V seminário internacional de pesquisa em Educação Matemática. Rio de Janeiro, 2012.

SILVA, Maria Regina Gomes da. Avaliação e trabalho em grupo em assimilação solidária: análise de uma intervenção. Rio Claro, 1997. Tese (Doutorado) - Universidade Estadual Paulista.

SILVA, Maria Regina Gomes da. Concepções sobre Assimilação Solidária num curso universitário. Ciência \& Educação, vol. 5, nํ⒉ Bauru, 1998.

SKOVSMOSE, Ole. Educação Matemática Crítica: A Questão da Democracia. Tradução de Abgail Lins e Jussara de Loiola Araújo. Campinas: Papirus, 2001.

STEWART, James. Cálculo. 4. ed. São Paulo: Pioneira Thomson Learning, 2001. 1v, il.

TORRES, Patrícia L. Laboratório online de Aprendizagem: uma proposta crítica de aprendizagem colaborativa para a educação. Tubarão: Ed. Unisul, 2004.

ZIMDARS, Eduardo Rafael. Pedagogia da Assimilação Solidária: Desafios e Possibilidades no Processo de Ensino e Aprendizagem de Limites. 203 f. Dissertação (Mestrado) - Pós-graduação em Ensino de Ciências, Matemática e Tecnologias, Universidade do Estado de Santa Catarina, Joinville, 2018. 